\title{
PARTICIPACIÓN Y PRESIDENCIALISMO EN LA CONSTITUCIÓN ECUATORIANA DEL 2008
}

\author{
PARTICIPATION AND PRESIDENTIALISM IN THE \\ EQUATORIAN CONSTITUTION OF 2008
}

\author{
PARTICIPAÇÃO E PRESIDENCIALISMO NA \\ CONSTITUIÇÃO EQUATORIANA DE 2008
}

\begin{abstract}
Agustín Grijalva*
Resumen: En el presente ensayo sugerimos algunas ideas preliminares para un balance de la participación y su relación con el presidencialismo en el nuevo constitucionalismo latinoamericano, con especial énfasis en el caso de Ecuador que durante la última década promulgó una de las Constituciones con mayores innovaciones en la región. Para este balance se realiza una contextualización básica del nuevo constitucionalismo latinoamericano y luego se analiza el desarrollo de la participación en Ecuador luego de promulgada la Constitución. Este análisis de la participación se lo relaciona con ámbitos claves como la política económica (especialmente minería, empresas públicas, formas cooperativas de economía) y la plurinacionalidad (especialmente justicia indígena y educación). Se describen y examinan críticamente casos hitos que por su importancia reflejan tendencias estructurales durante la vigencia de la Constitución ecuatoriana del 2008 hasta el presente.
\end{abstract}

Palabras clave: Constitución Ecuatoriana del 2008; Democracia directa; Nuevo constitucionalismo; participación política.

\begin{abstract}
In the present essay we suggest some preliminary ideas for a balance of participation and its relation to presidentialism in the new Latin American constitutionalism, with special emphasis on the case of Ecuador, which during the last decade promulgated one of the Constitutions with the greatest innovations in the region. For this balance, a basic contextualization of the new Latin American constitutionalism is made and then the development of the participation in Ecuador is analyzed after the promulgation of the Constitution. This analysis of participation is related to key areas such as economic policy (especially mining, public enterprises, cooperative forms of economy) and plurinationality (especially indigenous justice and education). For that, the cases that, due to their importance, reflect structural tendencies during the validity of the Constitution of Ecuador from 2008 to the present are described and critically examined.

Key words: Direct democracy; Ecuatorian Constitution of 2008; new Latin American constitutionalism; political participation.
\end{abstract}

Resumo: No presente ensaio sugerimos algumas idéias preliminares para um balanço da participação e sua relação com o presidencialismo no novo constitucionalismo latino-

\footnotetext{
* Jurista y politólogo, profesor de Derecho Constitucional, Universidad Andina Simón Bolívar, Sede Ecuador. E-mail: agustin.grijalva@gmail.com.
} 
americano, com especial ênfase no caso do Equador que, durante a última década, promulgou uma das Constituições com as maiores inovações na região. Para este balanço, é feita uma contextualização básica do novo constitucionalismo latino-americano e, em seguida, o desenvolvimento da participação no Equador é analisado após a promulgação da Constituição. Esta análise da participação está relacionada a áreas-chave como a política econômica (especialmente mineração, empresas públicas, formas cooperativas de economia) e a plurinacionalidade (especialmente a justiça e a educação indígenas). Para tanto, descreve-se e examina-se criticamente os casos que, devido à sua importância, refletem tendências estruturais durante a validade da Constituição do Equador a partir de 2008 até o presente.

Palavras-chave: Constituição equatoriana de 2008; democracia direta; novo constitucionalismo latino-americano; participação política.

\section{INTRODUCIÓN - EL NUEVO CONSTITUCIONALISMO}

El neoconstitucionalismo ${ }^{1}$, como se sabe, es una categoría teórica de origen europeo que hace relación a constituciones densas en derechos y garantías (AHUMADA, 2009). Este es el rasgo fundamental que esta tendencia constitucional comparte con el nuevo constitucionalismo latinoamericano o constitucionalismo transformador, y que debería traer aparejadas específicas, y diríamos que necesarias, consecuencias institucionales tales como el fortalecimiento de los jueces y en particular de los jueces y cortes constitucionales.

Sin embargo, hay otros aspectos que constituyen características propias e importantes del nuevo constitucionalismo latinoamericano, tales como el fortalecimiento de la participación política, la preocupación por la igualdad y la diversidad; los derechos sociales y colectivos, la regulación constitucional de la economía, la apertura al Derecho Internacional de los Derechos Humanos, y el laicismo (UPRIMNY, 2011).

En casos como los de Ecuador y Bolivia estas diferencias se acentúan en vista de la inclusión en los textos constitucionales de principios como el de Estado Plurinacional, la democracia comunitaria, los Derechos de la Naturaleza y el Buen Vivir. Estas preocupaciones propias del nuevo constitucionalismo latinoamericano pueden resumirse en una concepción amplia y radical de democracia, entendida más allá de las elecciones, en sus dimensiones política, cultural y económica ${ }^{2}$.

Las diferencias entre neoconstitucionalismo europeo y este nuevo constitucionalismo latinoamericano no son casuales. En realidad, responden a condiciones históricas tanto mediatas como inmediatas que antecedieron a los respectivos 
procesos constituyentes. Nada nuevo surge de la nada y este nuevo constitucionalismo tampoco puede escapar a la tradición constitucional de la región.

Respecto a las condiciones mediatas, el nuevo constitucionalismo latinoamericano tiene raíces propias en las corrientes constitucionales de democracia radical que se desarrollaron en el continente (GARGARELLA, 2014) en otros períodos históricos. El interés por la democracia ha sido una constante en las sociedades latinoamericanas, marcadas fuertemente por la exclusión y la desigualdad. La preocupación por los derechos sociales y económicos, por ejemplo, nos remite a múltiples constituciones latinoamericanas que los desarrollaron en las primeras décadas del siglo veinte, entre las cuales destaca por supuesto la Constitución mexicana. La necesidad de pensar nuevos modelos de constitución económica tiene relación directa con la historia latinoamericana del rol del Estado en la economía, y la proclamación del Estado plurinacional expresa nuestra experiencia histórica colonial, y la correspondiente lucha de los pueblos indígenas.

Respecto a las condiciones inmediatas o directas hay que recordar que a partir de los años noventa del siglo veinte estas constituciones buscaron ampliar la participación política de los ciudadanos y sus organizaciones. Esta fue una respuesta a la desilusión con la democracia representativa, y en especial con los partidos políticos y el poder legislativo, en muchos países de la región. Por otra parte, el importante fortalecimiento del rol del Estado en la economía fue claramente una respuesta a los procesos de privatización y desregulación del período neoliberal precedente. Así mismo, como ha planteado Boaventura de Sousa Santos el fortalecimiento de los derechos, especialmente los derechos sociales, económicos y culturales, vino a integrar una nueva promesa de la izquierda frente a la crisis de los países socialistas. En este contexto de protección y promoción de derechos se explica también la importancia que estas cartas dan formalmente a las garantías y a los jueces.

Sin embargo, hay una variable que muestra fuerte continuidad entre las constituciones de corte neoliberal y las del socialismo del siglo veintiuno. Es una continuidad que, a su vez, tiene remotos antecedentes en la historia latinoamericana. Se trata del inveterado fortalecimiento del Ejecutivo, y específicamente del presidente de la República. Esta continuidad se expresa en mayores poderes para el presidente, el debilitamiento del legislativo y el judicial, y en el caso del nuevo constitucionalismo en la posibilidad de reelección indefinida. ¿cómo se explica esta paradoja? 
En realidad, tanto estos gobiernos neoliberales como los del socialismo del siglo veintiuno contaron generalmente con presidentes que alcanzaron alta popularidad, mayorías legislativas e incidencia importante sobre los jueces constitucionales. Es bajo tales condiciones que estos presidentes promovieron incluso su reelección para llevar adelante sus programas. En el caso del neoliberalismo se buscó desarrollar programas de ajuste y estabilización macroeconómica, mientras que los gobiernos llamados socialistas buscaron impulsar una modernización de infraestructura y políticas de redistribución económica en base al aumento de ingresos estatales por exportaciones de petróleo, minerales $\mathrm{u}$ otros bienes primarios. En ambos casos, tanto para desregular como para regular, tanto para privatizar como para nacionalizar, se requerían ejecutivos fuertes con capacidad de imponerse a las resistencias sociales que generan estos procesos. Esta lógica llevó al hiperpresidencialismo.

El problema del hiperpresidencialismo es que constituye una dimensión o componente estructural claramente contradictorio con los demás postulados del nuevo constitucionalismo. La concentración de poder que implica el hiperpresidencialismo es contraria a la profundización de la democracia mediante la participación. Es también contraria al respeto a los derechos, los cuales por su condición siempre limitan y orientan al poder $^{3}$. En particular, dicha centralización del poder es contraría a un Estado Plurinacional, cuyo fundamento es la descentralización del poder y el reconocimiento de la diversidad de pueblos indígenas. Así mismo, es contraria a la independencia tanto del sistema judicial como de la jurisdicción constitucional y a la autonomía de los órganos de control. También hay una clara oposición entre hiper-presidencialismo y cualquier esquema de descentralización en el régimen territorial.

Por otra parte, como planteamos en una investigación sobre justicia indígena y plurinacionalidad en Ecuador y Bolivia (SANTOS; GRIJALVA, 2012) dirigida por Boaventura de Sousa Santos, la política económica extractivista del Estado requiere inhibir o al menos limitar los procesos de participación (como los de autonomía indígena, incluyendo su propia justicia). En efecto, dicha participación puede articularse directa o indirectamente como mecanismos de resistencia a las actividades extractivas que lleva adelante el Estado y las transnacionales. En cierto sentido en el presente estudio extendemos esta hipótesis desarrollada en dicha investigación a otras formas de participación.

\section{DEMOCRACIA DIRECTA Y PARTICIPACIÓN POLÍTICA}


Es claro que la democracia definida en varias de las más recientes constituciones latinoamericanas va más allá de la democracia representativa, pero la incluye. Es más, la propia democracia representativa viene, desde las reformas constitucionales de los años noventa, a ser redefinida en la región mediante la incorporación de formas de democracia directa y semidirecta u otros mecanismos de participación que incluyen el referéndum, el plebiscito, la revocatoria del mandato o la iniciativa legislativa.

Estos mecanismos, aunque potencialmente pueden enriquecer la democracia representativa, no deben ser tomados sin beneficio de inventario. Nuria Cunill (1997) ${ }^{4}$ ha sumarizado y analizado múltiples casos, en América Latina y en otras partes del mundo, en que las expresiones supuestamente mayoritarias o participativas han servido no para transformar relaciones de poder y redistribuir recursos más igualitariamente sino para legitimar el status quo e incluso facilitar reformas conservadoras.

De hecho, durante los años noventa las reformas constitucionales que en América Latina introducen mecanismos de participación directa como la iniciativa legislativa popular, el referéndum, el plebiscito y múltiples mecanismos de democracia participativa, coinciden con los procesos de reducción del Estado y transferencia de sus recursos y competencias al sector privado. Y es que, como indicábamos anteriormente, en muchas ocasiones la participación ciudadana ha sido reducida a un mecanismo puramente funcional a las necesidades de información y gestión de la burocracia o a las necesidades de control corporatista de gobiernos populistas y autoritarios, e incluso de dictaduras.

El precisar en qué condiciones la participación es realmente democrática y conducente a la efectivización de derechos humanos tiene especial importancia hoy en América Latina. Varios de los gobiernos que se presentan como progresistas en la región vienen organizando consejos ciudadanos de diversa índole. Es necesario estudiar críticamente estas experiencias a efectos de determinar de qué forma transforman o reproducen relaciones de poder y redistribuyen recursos. Una condición clave a tomar en cuenta es la evaluación de cómo estas formas de organización popular se relacionan con el Estado, y específicamente con el gobierno de turno. Sin autonomía y derechos habilitantes las experiencias participativas degeneran en mecanismos de control político con efectos excluyentes y autoritarios, es decir con efectos contrarios a lo que implica el fortalecimiento de la democracia. 
Participación y presidencialismo en la constitución ecuatoriana del 2008

Sin embargo, al instaurarse gobiernos latinoamericanos denominados progresistas y al dictarse nuevas constituciones o reformarse las existentes se produce paralelamente un crecimiento del Estado. ¿Ha significado este crecimiento una mayor y mejor participación política de los ciudadanos? ¿Cómo ha incidido dicha participación en la efectividad de los derechos y en la redistribución de poder y recursos económicos?

\subsection{La Participación en la Constitución ecuatoriana del 2008}

A diferencia de la Constitución codificada en 1998 que establecía la clásica división en legislativo, ejecutivo y judicial, la Constitución del 2008 establece cinco funciones, pues a las tres funciones clásicas agrega otras dos: la función electoral, y la de transparencia y control social. Esta última tiene como fin promover la participación, los derechos, el control de los servicios públicos y el combate a la corrupción (ECUADOR, 2008).

La Constitución del 2008 fortaleció nominalmente la participación de los ciudadanos en la gestión pública, la fiscalización y la lucha contra la corrupción. La Constitución ecuatoriana anterior, promulgada en 1998, ya establecía una Comisión de Control Cívico de la Corrupción que receptaba denuncias contra presuntos delitos para solicitar a las autoridades judiciales su juzgamiento y sanción (art. 220). La Constitución del 2008 transfiere estas competencias a esta nueva función del Estado, con igual jerarquía que las funciones ejecutiva, legislativa, judicial, y electoral, denominada Función de Transparencia y Control Social. (Art 204).

El principal organismo dentro de esta nueva Función del Estado es el Consejo Nacional de Participación Ciudadana y Control Social (art 207). Los miembros del Consejo de Participación son designados mediante concurso a realizarse luego de un proceso de impugnación de los candidatos, bajo veeduría ciudadana. Entre las funciones del Consejo se destacan la lucha contra la corrupción, promover la participación de los ciudadanos, y designar al Defensor del Pueblo, Defensoría Pública, Fiscal General, Contralor General, y miembros del Consejo Nacional Electoral y Tribunal Contencioso Electoral. (art 208).

Tras nueve años de vigencia de esta Constitución se puede concluir que, pese a concebirla como una nueva Función del Estado, y a la innovación que supuso la creación del Consejo de Participación Ciudadana, no ha mejorado la participación ciudadana ni el control sobre la corrupción pública ${ }^{5}$. Por el contrario, esta nueva Función ha contribuido 
al debilitamiento de la fiscalización por parte de los ciudadanos y de los órganos de control. Por otra parte, ha supuesto un desplazamiento del legislativo tanto en sus tareas fiscalizadoras como en la designación de los titulares de organismos públicos de control y de derechos humanos.

En efecto, este Consejo adolece de graves problemas de representatividad e incluso legitimidad política. Mientras que la noción de participación tiene que ver con la intervención directa, no mediada, de los ciudadanos en los asuntos de interés público, la conformación de este Consejo se basa en un concurso, es decir en supuestos y confusos méritos para seleccionar funcionarios que no tienen ninguna representatividad social o política, en tanto no han sido elegidos por nadie. De esta forma, en lugar de complementariedad se produce una confusión entre democracia participativa, democracia representativa y meritocracia.

El artículo 100 de la Constitución ecuatoriana establece además la posibilidad de organizar otros muchos mecanismos de participación ciudadana ${ }^{6}$ tales como audiencias públicas, cabildos populares, asambleas, consejos consultivos, observatorios y veedurías a efectos de aprobar planes de desarrollo en las diversas instancias territoriales e institucionales del Estado ecuatoriano. Se crean así mismo Consejos Nacionales de Igualdad, integrados por representantes de la Función Ejecutiva y de la sociedad civil, y cuya función es combatir la discriminación, marginación y exclusión.

En esa misma línea se fortalece lo que la Constitución denomina democracia directa, mediante la ampliación de la revocatoria del mandato a todas las autoridades públicas (art 105), así como la ratificación y mayor regulación constitucional de la iniciativa de la ciudadanía para presentar proyectos de ley (art 103). Incluso se delinean instituciones novedosas, como la de la silla vacía (posibilidad de un representante ciudadano en las sesiones públicas de gobiernos autónomos descentralizados) (art 101).

Los estudios empíricos sobre la implementación de estos numerosos mecanismos constitucionales de participación son aún escasos. Sin embargo, puede plantearse la hipótesis de un desarrollo muy desigual y en balance insuficiente o negativo. Por ejemplo, desde su tardía creación varios de los nuevos consejos tienen mayoría de delegados del Ejecutivo, están presididos por éstos (OSPINA, 2013) o tienen un desarrollo marginal (CÓRDOVA, 2013) y muy baja incidencia en procesos como la planificación (ORRANTÍA PARRA, 2015). La ampliación y regulación de la revocatoria del mandato derivó en cierta manipulación y abuso de esta institución (MALACATUS, 2016). Instituciones novedosas como la silla vacía son aún de escaza y confusa aplicación 
e incluso han sido distorsionados (CASTRO, 2014). Un resultado ejemplificativo en la misma dirección y especialmente preocupante ha sido el de una veeduría ciudadana integrada para revisar los contratos públicos a favor de un hermano del presidente Correa. En este caso, se iniciaron juicios penales contra dos de los cuatro veedores por su conclusión de que el presidente si conoció de tales contratos. Los veedores fueron sentenciados a un año de cárcel.

Así mismo, la Constitución en su artículo 95 caracteriza la participación como un derecho que se ejerce a través de los mecanismos de la democracia representativa, directa y comunitaria. El artículo 96 llega incluso a reconocer a todas las formas de organización de la sociedad como "expresión de la soberanía popular" para incidir en todas las decisiones y políticas públicas. En la práctica, sin embargo, lo que se ha producido es una criminalización de los defensores de derechos humanos y un ataque sistemático al derecho a la protesta $\operatorname{social}^{7}$ y al de asociación, tanto mediante figuras legales establecidas en el nuevo Código Integral Penal dictado por el régimen (sabotaje, terrorismo, rebelión, etc.) y aplicadas a numerosas protestas ${ }^{8}$, como mediante el Decreto 16 promulgado en Junio del 2013, el cual ha permitido al Ejecutivo la disolución de organizaciones contrarias a sus políticas ${ }^{9}$. Esta es una situación profundamente paradójica en un país cuya Constitución consagra incluso el derecho a la resistencia frente a acciones u omisiones del poder público que violen derechos (art. 98).

El diseño constitucional de la participación en la Constitución ecuatoriana del 2008 es, por tanto, en sí mismo contradictorio, y por otro lado las políticas del gobierno han sido más bien violatorias del derecho a la participación. Por un lado incluye una proliferación de mecanismos de participación, mientras que por otra parte "estatiza la participación", reduciéndola a una "función del Estado" diferenciada, cuando la participación debe ser un mecanismo transversal de todas las instituciones públicas, de todas las funciones del Estado en su relación con la sociedad, teniendo por cierto como eje preponderante a ésta última. Sin embargo, los titulares de la función de participación son designados por concurso, lo cual en la práctica ha facilitado su cooptación por parte del Ejecutivo ${ }^{10}$, esto a su vez ha viabilizado su injerencia en la designación de los titulares de los órganos de control ${ }^{11}$. De esta forma, una institucionalidad que debía propiciar la participación social, en realidad ha servido para despojar al legislativo de sus funciones de fiscalización y control político, controlar o reducir la participación ciudadana y en su lugar afianzar el hiper-presidencialismo. 
En efecto, conceptualmente podríamos distinguir a este respecto dos formas de participación: la participación como legitimación y la participación como democratización. La participación como legitimación es inducida en la sociedad y sus organizaciones verticalmente desde el poder del Estado, busca legitimar lo ya decidido o lo que va a decidirse luego a nivel de las élites políticas y la administración pública, privilegia la cantidad de talleres, reuniones, asambleas, etc., sobre su calidad; puesto que no democratiza las decisiones en realidad no redistribuye el poder político y tampoco necesariamente el económico. Un ejemplo muy claro sería la consulta no vinculante.

En contraste, la participación como democratización nace de las mismas organizaciones y movimientos sociales, busca democratizar efectivamente las decisiones y por tanto direcciona realmente a la burocracia estatal, no sacrifica nunca la calidad a la cantidad de reuniones o mecanismos participativos pues debe asegurar condiciones reales de información, igualdad, y seguimiento reales; por su naturaleza tiende a propiciar una redistribución real del poder público y de los bienes económicos y culturales. Un ejemplo muy claro de este tipo de participación son las mejores prácticas de presupuestos participativos (FUNG; WRIGHT, 2013).

A continuación, para ilustrar esta diferencia, examino el caso de la consulta popular convocada en Ecuador por el presidente Rafael Correa en 2011. Como veremos, este es un claro ejemplo de participación legitimadora que por vía de restricción de la independencia judicial concentró en lugar de redistribuir el poder. Luego se examinan otras dos consultas populares frustradas o bloqueadas por el gobierno de Correa, lo cual corrobora la tesis mencionada de la instrumentalización de la participación.

Ecuador, en particular, ha realizado desde su regreso a la Democracia en 1978 numerosos referéndums y consultas populares sobre los más diversos temas. Esta nación comparte con Uruguay la condición de ser uno de los países con mayor número de referéndums y plebiscitos en la región. Sin embargo, hay importantes diferencias puesto que, en Uruguay, a partir de 1989 y el regreso a la democracia, muchos plebiscitos y referéndums han sido impulsados por los propios ciudadanos y sus organizaciones, mientras en Ecuador hasta el 2008 han sido los presidentes los que han recurrido a este mecanismo para consolidarse o legitimarse en el poder.

\subsection{La Consulta Popular del 2011}


La consulta popular de 7 de mayo del 2011 en Ecuador muestra justamente como una participación plebiscitaria puede ser utilizada para legitimar una mayor concentración del poder, en lugar de su democratización. Esta consulta permitió al presidente Correa aumentar significativamente la injerencia del Ejecutivo y otras instancias públicas bajo su influencia en la designación de los miembros del Consejo de la Judicatura, erosionando de esta forma el diseño que la Constitución había previsto para resguardar la independencia judicial.

En febrero del 2011, Correa convocó simultáneamente a un referéndum y a una consulta popular. En Ecuador, lo primero se refiere a una reforma a la Constitución, y lo segundo a asuntos que el presidente considera de gran importancia pública (ECUADOR, 2008). Entre referéndum y consulta se incluyeron en total diez preguntas sobre muy diversos temas. Lo fundamental, sin embargo, se hallaba en una reforma constitucional a la forma de integración del Consejo de la Judicatura.

Las preguntas 4 y 5 del referéndum convocado por el presidente Correa plantearon una reforma a la Constitución, así como a varios artículos del Código Orgánico de la Función Judicial. El principal cambio implicaba disolver el Consejo de la Judicatura en funciones y nombrar un Consejo de Judicatura de Transición por un plazo de 18 meses, integrado por tres miembros, uno designado por la Función Ejecutiva, otro por la Función Legislativa, y otro por la Función de Transparencia y Control Social ${ }^{12}$. Luego de este lapso debía nombrarse un Consejo de la Judicatura definitivo con una diferente composición en base a las nuevas reglas que reformaban la Constitución. El nuevo Consejo de la Judicatura pasaba a estar integrado por 5 delegados y sus suplentes, elegidos por el Consejo de Participación Ciudadana y Control Social de ternas enviadas por el presidente de la Corte Nacional de Justicia, El Fiscal General del Estado, el Defensor Público, por la Función Ejecutiva y por la Asamblea Nacional. La reforma incluyó además varios cambios en la estructura funcional y atribuciones de las instancias internas del Consejo de la Judicatura.

En lo principal, esta reforma cambió el diseño institucional concebido originalmente en la Constitución del 2008 para la integración del Consejo de la Judicatura. En esta Constitución el Consejo de la Judicatura era un órgano que se integraba y funcionaba de forma autónoma respecto de las demás funciones del Estado, sin participación de delegados de ninguna de ellas. La Constitución preveía la designación de los nueve miembros del Consejo de la Judicatura mediante un concurso público de méritos y oposición en que se combinaban profesionales de Derecho y Administración. 
Este concurso debía ser organizado por el Consejo de Participación Ciudadana y Control Social (ECUADOR, 2008). El referéndum propuesto por el presidente Correa cambió totalmente este modelo.

La reforma propuesta por el presidente Correa implicaba una reforma constitucional de orden orgánico sujeto a control constitucional. Por tal razón, la Corte Constitucional examinó las preguntas para determinar si el procedimiento adoptado era el adecuado.

Conforme al Artículo 441 de la Constitución ecuatoriana el presidente solo puede someter a referéndum reformas a la Constitución que no alteren la estructura fundamental o el carácter y elementos constitutivos del Estado. En consecuencia, se produjo un debate entre quienes se oponían a la consulta, aduciendo que la reforma a la integración del Consejo de la Judicatura alteraba la estructura del Estado, y el Ejecutivo que afirmaba que la reforma no tenía dicho alcance ${ }^{13}$. Esta división de criterios se generó también en el seno de la Corte Constitucional, cuya mayoría de magistrados planteó, en consonancia con el Ejecutivo, que la forma de designación de los miembros del Consejo de la Judicatura era un asunto distinto y sin relación con la independencia de los mismos.

En resumen, la mayoría de la Corte esgrimió dos argumentos centrales: 1) la forma de elección de los miembros del Consejo de la Judicatura no afecta la independencia ni la estructura del Estado; y, 2) debe en todo caso prevalecer la decisión democrática de la mayoría de ciudadanos que se puede y debe expresar en el referéndum. Ante estos argumentos, la minoría de la Corte presentó una visión contraria, según la cual la forma de designación de los miembros del Consejo de la Judicatura tiene directa relevancia para la independencia judicial. La razón de ello, como se dijo, es que en la historia constitucional ecuatoriana tanto el Ejecutivo como el Legislativo han buscado, por razones político-partidistas, controlar a los jueces mediante su destitución y designación. Justamente por esta razón la Constitución ecuatoriana eliminó la participación de estas funciones en la elección de los miembros del Consejo.

Finalmente, los resultados del referéndum favorecieron al gobierno en todas las preguntas, aunque el margen con el cual el presidente ganó en el caso de las preguntas sobre el Consejo de la Judicatura fue reducido (53.8 \%). El caso de Ecuador muestra como la democracia plebiscitaria puede erosionar la independencia judicial. Incluso, hay graves cuestionamientos y preocupaciones respecto a la independencia de los jueces y a condiciones institucionales del sistema de justicia. De hecho, las veedurías e informes internacionales que han estudiado la designación de nuevos jueces o en general el sistema 
judicial $^{14}$ en Ecuador han formulado observaciones que confirman la existencia de estos problemas.

En definitiva, los límites al Poder Ejecutivo fueron afectados por los resultados del referéndum al menos en dos sentidos. Primero, porque el Ejecutivo en Ecuador ha vuelto a tener una injerencia directa en la designación y remoción y por este medio en las decisiones de los jueces ${ }^{15}$. Y segundo, porque el debilitamiento de la independencia judicial implica un menor control sobre el Ejecutivo, erosionando así el Estado de Derecho y favoreciendo la corrupción.

\subsection{Bloqueo a nuevas consultas}

Bajo la Constitución del 2008 se ha discutido la necesidad de una consulta popular a nivel nacional en otras tres ocasiones. Primero, en relación con el Proyecto Yasuní ITT iniciado en el 2007; segundo, respecto a un conjunto de reformas constitucionales impulsadas por Correa a finales del 2015, entre las que se incluye la reelección indefinida. Finalmente, Rafael Correa ha convocado a una consulta popular para el 19 de febrero del 2017 sobre crear una prohibición legal de inversiones de funcionarios públicos en paraísos fiscales.

En cuanto al Proyecto Yasuní ITT, hay que aclarar que básicamente consistió en mantener inexplotados unos 856 millones de barriles de petróleo en el subsuelo de una zona intangible de la Amazonía ecuatoriana de alta biodiversidad y en la que viven además pueblos indígenas no contactados. Al mantener bajo tierra el petróleo, Ecuador disminuiría la contaminación del ambiente, daños ecológicos y culturales al evitar la emisión de 407 millones de toneladas métricas de dióxido de carbono a cambio de pagos internacionales por unos 350 millones de dólares anuales, a modo de compensación por ingresos no percibidos.

Esta iniciativa de mantener el petróleo bajo tierra correspondía a lo establecido en el artículo 407 de la Constitución ecuatoriana, en el cual se prohíbe clara y expresamente cualquier actividad extractiva en zonas declaradas intangibles, salvo declaración de interés nacional solicitada por el presidente. Esta excepción era inaplicable en el caso del Yasuní, pues el artículo 57 de la carta, en su parte final, prohíbe de forma absoluta tal explotación en zonas habitadas por pueblos indígenas no contactados ${ }^{16}$.

Sin embargo, el 15 de agosto del 2013, al no recaudar suficientes fondos internacionales, el gobierno de Correa dio por terminada la iniciativa ITT para la no 
explotación del Yasuní. Ante esta decisión varias organizaciones populares y el colectivo Yasunidos iniciaron una campaña nacional de recolección de firmas para la convocatoria a una consulta popular en que se respaldara la no explotación del Yasuní ${ }^{17}$. Luego de varios meses y dificultades de procedimiento se llegaron a recoger 673.862 firmas que fueron presentadas al Consejo Nacional Electoral el 12 abril del 2014. Sin embargo, luego de varios actos de violación al debido proceso, represión y agresión mediática, se anularon ilegalmente miles de estas firmas, impidiendo así la consulta.

La frustrada consulta popular sobre el Yasuní ilustra claramente el desfase entre, por un lado, los postulados constitucionales de participación, derechos de la naturaleza y de los pueblos indígenas en un estado proclamado plurinacional e intercultural, y por otro lado la actuación real del gobierno de Correa. Pese al amplio respaldo en la opinión pública para evitar la explotación del Yasuní, que buscó expresarse mediante la consulta, el presidente Correa mediante decreto dio por terminada la iniciativa ITT y declaró de interés nacional la explotación del Yasuni, lo cual fue ratificado por la mayoría oficialista en la Asamblea Nacional. Correlativamente, la Corte Constitucional y el Consejo Nacional Electoral, también alineados con la posición del Ejecutivo, actuaron para bloquear la consulta popular.

En definitiva, toda la institucionalidad estatal actuó de forma sistemática y coordinada para violar los derechos de participación, ambientales y de los pueblos indígenas, en función de la política extractivista del régimen. El gobierno, paradójicamente, como ha sucedido en otros países de América Latina, usó como principal argumento para dicha explotación la necesidad de recursos económicos para financiar la satisfacción de los derechos sociales de los más pobres.

Una segunda discusión sobre la pertinencia o no de una consulta popular se refirió a 16 enmiendas constitucionales presentadas en el 2015 a la Asamblea Nacional por Alianza País, el partido de gobierno, entre las cuales se incluyó restricciones a la consulta popular, a los derechos de asociación y huelga, y de comunicación, disminución de competencias de la Contraloría y ampliación de competencias de las Fuerzas Armadas en el resguardo del orden interno, así como la reelección indefinida del Presidente de la República y demás autoridades de elección popular.

La oposición al gobierno de Correa insistió en que esta reforma constitucional sea realizada mediante una consulta popular o referéndum, en vista de su importancia política y de sus efectos justamente sobre los derechos y la democracia. Sin embargo, el gobierno de Correa se rehusó a procesar la reforma vía referéndum y, valiéndose de su 
mayoría legislativa e injerencia en la Corte Constitucional, tramitó y aprobó la reforma vía enmienda en la Asamblea Nacional en diciembre del 2015, si bien mediante una disposición transitoria no se dio aplicación inmediata a la reforma que introdujo la reelección indefinida, excluyendo así, por esta ocasión, la posibilidad de reelección de Correa.

Es notorio que las reformas propuestas por el bloque legislativo oficialista apuntaron todas en dirección a la restricción de varios derechos de participación. En efecto, la reforma constitucional limitó la institución misma de la consulta popular al exigir que esta se refiera a materias dentro de las competencias legales de los municipios y otros gobiernos seccionales autónomos. La reforma también restringió, como analizamos luego, los derechos de sindicalización, negociación colectiva y huelga de trabajadores públicos. Por otra parte, fortaleció la capacidad de control y represión interna al extender estas funciones a las Fuerzas Armadas. Lamentablemente este no es un fenómeno aislado, al igual que en otros países de América Latina con constituciones progresistas, en Ecuador durante la fase postconstituyente se ha desarrollado legislación, jurisprudencia, políticas públicas e incluso reformas constitucionales que en lugar de desarrollar tales derechos los han restringido o, abiertamente, violado.

Así, por ejemplo, el establecimiento de la reelección indefinida en Ecuador, al igual que en Venezuela, Nicaragua y Bolivia, devela un grave deterioro de la democracia representativa en estos países. En lugar de complementar y enriquecer la democracia representativa, mediante el ejercicio de los numerosos mecanismos de democracia directa y de participación, como lo establecen las constituciones de estos países, lo que observamos en la práctica es una grave distorsión de los procesos electorales (ORTIZ, 2017). En esta distorsión han participado además de manera dependiente del Ejecutivo tanto las legislaturas como los jueces constitucionales.

En efecto, la reelección presidencial indefinida evidencia la adscripción personalista a un líder por parte de los movimientos y organizaciones que apoyan al gobierno de turno. De este modo, en lugar de fortalecer la participación de las organizaciones populares para dar continuidad a proyectos de cambio, lo que se ha ido gestando es una desinstitucionalización general de partidos y movimientos políticos en torno a una cultura política crecientemente caudillista y por tanto excluyente de una mayor y mejor participación.

Más recientemente el presidente Correa convocó a una consulta popular sobre la prohibición de que las autoridades de elección popular y servidores públicos puedan 
tener bienes o capitales de cualquier naturaleza en paraísos fiscales. Esta consulta se realiza el 19 de febrero del 2017, la misma fecha de las elecciones presidenciales y legislativas. Nuevamente se trata de una iniciativa por decreto tomada por el presidente y avalada por la Corte Constitucional en una coyuntura de fuerte polarización y rivalidad electoral, en un país con fuertes escándalos por la remisión de recursos a paraísos fiscales, a partir del panamá papers.

La Consulta popular del 2011, al igual que la negativa del gobierno de Correa en el 2013 para dar paso a la participación democrática sobre la iniciativa Yasuní ITT, y las enmiendas constitucionales del 2015, incluyendo la reelección indefinida, como la más reciente consulta sobre paraísos fiscales, muestran el uso selectivo y sesgado del referéndum o consulta popular. Esta se ha utilizado no como un mecanismo de efectiva ampliación de la participación popular en la toma de decisiones desde la sociedad hacia el Estado. Por el contrario, la participación ha devenido en un recurso político selectivo para impulsar e imponer a la sociedad, verticalmente desde el Estado, las reformas e iniciativas que el gobierno coyunturalmente quiso llevar adelante y legitimarlas, incluso violando la propia Constitución.

\section{PARTICIPACIÓN Y ESTADO PLURINACIONAL E INTERCULTURAL}

Otra innovación del nuevo constitucionalismo latinoamericano consiste en la proclamación formal en las constituciones de Estados interculturales y, en los casos de Bolivia y Ecuador, además estados Plurinacionales. En este acápite se formula evaluaciones iniciales del efecto de las innovaciones normativas de la Constitución ecuatoriana del 2008 sobre participación y pueblos indígenas.

El movimiento indígena ecuatoriano desarrolló desde los años ochenta del siglo veinte una definición de los pueblos indígenas como nacionalidades y la consiguiente necesidad de un Estado plurinacional, lo cual implica un reconocimiento de la diversidad cultural que se proyecta institucionalmente y políticamente en la estructura del Estado (SANTOS, 2010).

La Constitución ecuatoriana de 1998 definía ya al Estado ecuatoriano como pluricultural y multiétnico ${ }^{18}$. Aunque esta fórmula podría verse como culturalista y estática frente al énfasis más político y de interacción cultural de la Constitución del 2008 al declarar claramente al Estado ecuatoriano como intercultural y plurinacional. Lo cierto es que la Constitución de 1998 establecía también un amplio catálogo de derechos 
colectivos y diversas referencias a las culturas indígenas en materias como idiomas, salud o educación; pero estos derechos y referencias fueron ampliados y enriquecidos por la Constitución del 2008, si bien la misma no llegó a establecer un parlamento y otras instituciones plurinacionales, como lo exigieron algunas organizaciones indígenas.

El problema que estas innovaciones plantean es el de la relación de un presidencialismo exacerbado, como el incluido en la Constitución del 2008, con el Estado Plurinacional e Intercultural que también la propia carta proclama. Por supuesto, hay una contradicción en el diseño constitucional mismo, pues la autonomía, participación, descentralización y heterogeneidad propia de un Estado Plurinacional entran en colisión directa con la centralización y homogenización inherentes al hiperpresidencialismo. En lo que sigue evidenciamos esta contradicción mediante el análisis del funcionamiento de la participación en los casos de la consulta pre-legislativa, la educación intercultural bilingüe y la justicia indígena.

\subsection{Consulta y Minería}

Entre los nuevos derechos colectivos de los pueblos indígenas, reconocidos por la Constitución del 2008, se incluyó la consulta pre-legislativa, es decir el derecho a ser consultados antes de la adopción de medidas legislativas que puedan afectarlos (ECUADOR, 2008).

Las políticas de minería durante los años de vigencia de la Constitución de Montecristi evidencian la brecha entre la declaratoria constitucional de plurinacionalidad y los derechos colectivos indígenas, por un lado, y la lógica extractivista de un Estado que viola los derechos colectivos de participación y autonomía, y otros derechos culturales y ambientales de los pueblos indígenas.

Ya en el 2007, incluso antes de promulgarse la Constitución de Montecristi, se produjeron protestas populares por el proyecto de Ley de Minería por lo cual el gobierno de Correa suspendió actividades en el sector y llamó a un diálogo minero con las organizaciones sociales. La constituyente dicta entonces un mandato minero por el que se revierten al Estado la mayor parte de las concesiones. Pese a estas medidas, el 29 de enero del 2009 se aprueba la Ley de Minería y ya para febrero y Marzo de ese año se reinician las protestas populares contra esta legislación. En este contexto, la Confederación de Nacionalidades Indígenas del Ecuador (CONAIE) demandó la 
inconstitucionalidad de esta Ley (CORTE CONSTITUCIONAL DEL ECUADOR, 2014).

Un argumento central en la demanda de la CONAIE consistió justamente en la falta de participación de los pueblos indígenas al haberse violado su derecho a consulta pre-legislativa. En efecto, la Constitución de Montecristi en su artículo 57 numeral 7 establece el derecho colectivo a "la consulta previa, libre e informada, dentro de un plazo razonable, sobre planes y programas de prospección, explotación y comercialización de recursos no renovables que se encuentran en sus tierras y que puedan afectarles ambiental o culturalmente" (ECUADOR, 2008). En el mismo sentido, el numeral 17 de este artículo establece, como indicábamos, su derecho a ser consultados antes de cualquier medida legislativa que pudiere afectarles.

A pesar de lo claro de estas disposiciones constitucionales, la Asamblea Nacional durante el procedimiento legislativo no llevó adelante una verdadera consulta a los pueblos indígenas potencialmente afectados, en su lugar se realizaron algunos talleres de socialización orientados más bien a la legitimación de la ley. De hecho, la Corte Constitucional en su sentencia no declaró la inconstitucionalidad de la ley y estableció en base a normativa internacional diversos estándares ${ }^{19}$ de consulta, que dichos talleres paradójicamente no cumplieron.

Es interesante notar que durante el proceso constitucional los abogados tanto de la Presidencia de la República como la Asamblea Nacional argumentaron que en este caso lo que debía practicarse era una consulta ambiental, conforme a lo establecido en el artículo 398, y no una consulta pre-legislativa aplicable a los pueblos indígenas. Incluso la propia Ley de Minería en su artículo 87 se refería exclusivamente a la consulta ambiental. De esta forma, se generó por parte del gobierno y su mayoría legislativa una estrategia de invisibilización por la cual se desconocía la especificidad del derecho colectivo de los pueblos indígenas a la consulta pre-legislativa, la cual la Constitución clara y expresamente reconoce. De hecho, la Ley de Minería, pese a su incidencia sobre los pueblos indígenas, no hace ninguna referencia a las comunidades y pueblos y nacionalidades indígenas salvo alguna referencia aislada a regalías en su artículo 40.

Puesto que el gobierno de Correa impulsó la explotación minera en varias localidades del país, han sido frecuentes los conflictos con las comunidades indígenas que habitan en esas áreas en vista del fuerte impacto ambiental, cultural y social que implica dicha explotación. En estos casos, la ausencia de consulta, la represión y criminalización de la protesta ha sido un patrón común durante el período de la Revolución Ciudadana. 
Participación y presidencialismo en la constitución ecuatoriana del 2008

Cuando se ha consultado a la comunidad local sobre la explotación minera, como en el caso de la comunidad indígena de Quimsacocha (NOGUERA; NAVAS, 2016) en que se respetaron los parámetros adecuados para este proceso, el gobierno ha desconocido los resultados.

\subsection{Educación intercultural bilingüe}

La Constitución del 2008 desarrolló y amplió formalmente la participación de los pueblos indígenas en el sistema intercultural bilinguie, el cual ya había sido reconocido en la Constitución de 1998. Así, por ejemplo, el artículo 57 numeral 14 de la Constitución de Montecristi expresamente indica que "[...] La administración de este sistema será colectiva y participativa, con alternancia temporal y espacial, basada en veeduría comunitaria y rendición de cuentas" (ECUADOR, 2008). Este mismo artículo, de forma más amplia, en el numeral 16 establece el derecho colectivo indígena a “[...] participar mediante sus representantes en los organismos oficiales que determine la ley, en la definición de las políticas públicas que les conciernan, así como en el diseño y decisión de sus prioridades en los planes y proyectos del Estado" (ECUADOR, 2008).

Pese a estos postulados constitucionales, en el 2011 se dictó la Ley Orgánica de Educación Intercultural (LOEI), la cual, aunque reitera estos principios centralizó la toma de decisiones en la autoridad educativa nacional y, correlativamente, debilitó la participación y autonomía de la gestión educativa de los pueblos indígenas. En efecto, en 1992 se creó mediante decreto ejecutivo la Dirección de Educación Intercultural Bilingüe, la cual actuó con autonomía administrativa y financiera. Sin embargo, la LOEI restó autonomía e integró a esta instancia institucional a un sistema nacional centralizado mediante la creación de la Subsecretaria de Educación Intercultural Bilingüe, la cual depende del respectivo ministro, disminuyendo así los niveles de participación de los pueblos indígenas en el manejo de su propia educación (BUSTOS, 2014).

Adicionalmente, pese a que la LOEI incluye numerosas normas que afectan directamente a los pueblos indígenas, ésta no fue sometida a consulta pre-legislativa como lo dispone el artículo 57 numeral 17 de la Constitución. De esta forma esta ley, incluso en cuanto al procedimiento de su aprobación, significó una violación al derecho a la participación de los pueblos indígenas, lo cual es una de varias condiciones para la declaratoria de su inconstitucionalidad. 
Una situación especialmente problemática en la educación intercultural es el cierre de cientos de escuelas comunitarias bilingües y, en varios casos, su reemplazo por las llamadas escuelas del milenio, centros educativos modelo creados por el gobierno y dotados de moderna infraestructura y tecnología de comunicación, que responden a un modelo único: escuelas de más de mil estudiantes, con nueva infraestructura, equipamiento, laboratorios y planta pluridocente, que agrupan y reemplazan a pequeñas escuelas comunitarias.

Es cierto que muchas pequeñas escuelas comunitarias se hallaban en condiciones materiales deplorables, lo cual afectaba la calidad de la educación, pero varias escuelas del milenio, en vista de su ubicación física a veces lejana del hogar de los niños y niñas indígenas, han generado graves problemas de acceso geográfico. Se cuestiona también el proceso pedagógico en las escuelas del milenio y el cierre de las escuelas comunitarias, dado el decisivo rol de estas últimas en la identidad y reproducción cultural y social de cada comunidad indígena.

Otro efecto de la centralización ha sido la sustitución de currículos, textos escolares, políticas y procesos de capacitación que anteriormente incluían cierta dimensión intercultural por otros de carácter nacional que ignoran la diversidad cultural y la diversidad linguística. Por otra parte, no se cuenta con los docentes bilingües adecuadamente capacitados para esta educación intercultural.

En realidad en materia de educación intercultural no es exagerado plantear que la activa y permanente participación de las comunidades y pueblos indígenas es indispensable para que efectivamente se respete el derecho a la educación, y específicamente las obligaciones del Estado de proveer este tipo de educación (disponibilidad) pero de forma que sea accesible y adecuada a la realidad cultural de estos pueblos (aceptabilidad y adaptabilidad), lo cual está necesariamente vinculado a la calidad (BUSTOS, 2014).

En definitiva, durante estos años de vigencia de la Constitución de Montecristi se ha producido una fuerte centralización institucional y homogenización cultural, contraria a la participación de los pueblos indígenas que es consustancial al Estado Plurinacional. Si bien la normativa constitucional y legal garantizan reiteradamente la autonomía y participación de los pueblos indígenas en la educación, en la práctica las políticas públicas han tomado otra dirección.

En nombre de la calidad de la educación se ha generado una política pública de modernización autoritaria que ha debilitado la participación indígena y está teniendo R. Fac. Dir. UFG, v. 41, n.2, p.134-168, maio / ago. 2017 
efectos integracionistas sobre estos pueblos, con lo cual se contraria abiertamente los postulados del Estado Plurinacional e Intercultural. Por el contrario, dicho modernización viene a actuar como un proceso neocolonial con graves efectos de aculturación sobre los pueblos indígenas.

Este proceso de modernización neocolonial prescinde de la participación de los pueblos indígenas puesto que se implementa como una política autoritaria y vertical desde el Ejecutivo. En este sentido, dichas políticas públicas impulsan una dinámica deconstituyente o de desconstitucionalización, puesto que se orientan en sentido contrario al horizonte plurinacional e intercultural trazado por la Constitución de Montecristi. En efecto, lo que resulta tremendamente paradójico es que es que este tipo de políticas se implementen justamente cuando se ha desarrollado una fuerte base normativa constitucional y legal, nacional e internacional, de reconocimiento de la diferencia cultural.

\subsection{Justicia Indígena}

El grado de desarrollo del pluralismo jurídico en un país es, a su vez, una medida clave del desarrollo del Estado Plurinacional e Intercultural. Puesto que el Estado Nacional tiene entre sus características definitorias el monopolio de la justicia y la coerción, la coexistencia de diversos sistemas de justicia indígena con normas y autoridades propias constituye una expresión no solo de diversidad sino de plurinacionalidad. Por otra parte, los sistemas de justicia indígena por su naturaleza comunitaria, y sin desmedro de su amplia heterogeneidad, generan procesos participativos de los miembros de cada comunidad indígena, son una forma de democracia comunitaria que Boaventura de Sousa Santos ha denominado democracia intercultural (SANTOS, 2010).

El pluralismo jurídico propio de un Estado Plurinacional es, a su vez, necesariamente contrario a un sistema hiper-presidencial puesto que éste último es opuesto a la descentralización, diversidad y autonomía que supone la coexistencia de múltiples sistemas normativos. Esta tensión entre plurinacionalidad, participación e hiper-presidencialismo está presente en la Constitución del 2008 y se ha expresado de múltiples formas a lo largo del tiempo de vigencia de la Constitución. A continuación, comparamos dos casos de justicia indígena paradigmáticos en este sentido, los casos de 
La Cocha, cuya comparación entre sí provee algunos indicadores del desarrollo de la plurinacionalidad en Ecuador.

Los casos de justicia indígena de la comunidad La Cocha están sin duda entre aquellos de este tipo que más atención judicial, mediática y política han recibido en el Ecuador. Tanto en el 2002 como en el 2010 las autoridades indígenas de esta comunidad aplicando su Derecho propio juzgaron casos de homicidios cometidos por indígenas contra indígenas. Se planteó por tanto en ambos casos el problema de si la justicia ordinaría podía y debía volver a juzgar y sancionar por estos homicidios. En ambos casos participaron jueces y tribunales de la justicia ordinaria y constitucional, mientras los medios de comunicación realizaron una intensa cobertura de los hechos, y en la opinión pública se desató un debate sobre los alcances y límites de la justicia indígena.

Aunque cada caso, el del 2002 y el 2010, tiene sus especificidades, ambos tienen importantes aspectos comunes y es interesante observar que, en el intervalo, en el 2008, se dictó la nueva Constitución del Ecuador, declarando al Estado Plurinacional e Intercultural, y fortaleciendo los derechos colectivos indígenas. Uno esperaría, por tanto, una evolución positiva a partir del 2008 en relación al reconocimiento de la justicia indígena.

En el 2002 el entonces Tribunal Constitucional finalmente se declaró incompetente para resolver sobre las decisiones de la justicia indígena debido a que consideró que implicaba un problema de competencias para cuya solución no tenía atribuciones constitucionales. En el 2010, en cambio, la Corte Constitucional, luego de un proceso que duró cuatro años, resolvió que la justicia indígena no tenía ni la capacidad cultural ni la competencia jurídica para resolver sobre homicidios (CORTE CONSTITUCIONAL DEL ECUADOR, 2014), pese a que la Constitución del 2008 proclama el Estado Plurinacional y otorga a la justicia indígena una competencia amplia, sin restricciones.

Mas allá de las diferencias empíricas y jurídicas entre estos dos casos, puede constatarse que la jurisdicción constitucional transitó de una estrategia consistente en ignorar a la justicia indígena a otra estrategia de restringirla. En el 2002, el Tribunal Constitucional decide no decidir, pero en el 2010 la Corte Constitucional excluye, directa y explícitamente, al juzgamiento de delitos contra la vida de las competencias de la jurisdicción indígena.

En la sentencia del 2010 la Corte, luego de invocar la plurinacionalidad, el pluralismo jurídico, la autonomía y los derechos colectivos, consideró que los sistemas R. Fac. Dir. UFG, v. 41, n.2, p.134-168, maio / ago. 2017 
de justicia de los pueblos indígenas no protegen jurídicamente la vida en vista de que, según la Corte, su concepción comunitaria da preeminencia a la armonía social y no concibe a la vida como derecho subjetivo. La argumentación de la sentencia no solo es contradictoria, sino que en realidad se aleja de los peritajes antropológicos practicados en el proceso y devela un acendrado etnocentrismo antitético a los valores del Estado Plurinacional. En consecuencia, la segunda sentencia sobre la Cocha es en realidad mucho más restrictiva, pese a que para la fecha en que se dictó ya estaba vigente la nueva Constitución que declaró al Ecuador como Estado Plurinacional y también ciertas normas legales sobre justicia indígena.

La sentencia de la Cocha del 2010 es expresión de un proceso más amplio que implica el endurecimiento de las penas mediante la promulgación para esas fechas de un nuevo Código Integral Penal, en el cual se aumenta el número de años de cárcel en la sanción de los delitos contra la vida. Por otra parte, la sentencia se dicta en un momento de fuerte regulación estatal sobre la actividad de los medios de comunicación privados, restricción de las iniciativas ciudadanas de consulta popular, imposición de una nueva Ley de Recursos Hídricos, y división del movimiento indígena en organizaciones opuestas y afines al gobierno. Es en medio de este proceso de fortalecimiento y concentración del poder del gobierno central que la sentencia de La Cocha reafirma el monopolio del Estado Nacional para sancionar.

El precedente jurisprudencial de la sentencia La Cocha del 2010, por otra parte, priva a las comunidades indígenas de la posibilidad de participar en juzgamientos por causa de homicidio. La justicia indígena se caracteriza justamente por incluir en sus procedimientos una activa participación de los miembros de la comunidad. Por ejemplo, en el caso de la Cocha se convocó a una asamblea general a la que concurrieron dirigentes de 24 comunidades que luego de 15 días de investigaciones impusieron sanciones a los agresores, las cuales la sentencia desconoció.

Estos procesos de participación comunitaria, así como las decisiones de las autoridades indígenas, pese a ser derechos colectivos constitucionales, bajo los parámetros de la sentencia de La Cocha pueden ser ahora fácilmente criminalizados. Con este precedente jurisprudencial, los actos de participación en los procesos de justicia indígena podrían considerarse como delitos de plagio, tortura, lesiones y usurpación de funciones, pese a que tanto la Constitución como la ley y la propia sentencia de la Cocha reiteran una y otra vez el carácter plurinacional e intercultural del Estado, así como los 
derechos colectivos de los pueblos indígenas, incluyendo su derecho a su propia justicia, autoridades y procedimientos.

Así como las escuelas comunitarias, la justicia indígena es una fuente vital de reproducción social de la comunidad, constituye una realidad sociológica que constituye una suerte de vanguardia anticipatoria del Estado Plurinacional que está por construirse (SANTOS; GRIJALVA, 2012). En este sentido, las restricciones y criminalización de la justicia indígena son pasos en dirección contraria a la participación y respeto a la diversidad inherentes a este nuevo tipo de Estado.

En realidad, el caso la Cocha es uno entre muchas expresiones de este proceso de recolonización en la administración de justicia, y en general de limitación a la autonomía de los pueblos indígenas y criminalización del ejercicio de sus derechos colectivos mediante juicios penales a las autoridades indígenas ${ }^{20}$. Estos casos evidencian la criminalización de la participación comunitaria, lo cual es paradójico si consideramos que la Constitución ecuatoriana promueve a lo largo de todo su texto diversas formas de participación e incluso consagra el derecho a la resistencia. Estos procesos de criminalización se han extendido durante estos últimos años del gobierno de Correa y se aplican en su gran mayoría a indígenas que han participado en protestas en diversas zonas del país contra inconsultos proyectos de explotación minera y petrolera. Tales protestas, a su vez, se extienden cada vez más conforme avanza la explotación minera en territorios indígenas o cerca de ellos.

Al examinar los diez años de gobierno de Rafael Correa en relación a la construcción del Estado Plurinacional el balance es negativo: no se ha gestado en este lapso un nuevo Estado de carácter plurinacional e intercultural. Al igual que bajo la Constitución de 1998, con la Constitución del 2008 solo algunas instituciones públicas especializadas han incorporado la problemática de la interculturalidad, pero no se ha avanzado en la construcción de un nuevo tipo de Estado en que las instituciones, la democracia, los derechos y la justicia funcionen en clave plurinacional.

\section{PARTICIPACIÓN Y ECONOMÍA}

Un cambio que nadie discute pero que se valora de muy diversas formas por distintos sectores es el del fortalecimiento del Estado a partir de la Constitución del 2008. En materia económica esto significó un fuerte crecimiento del sector público de la 
economía. ¿correspondió tal crecimiento al modelo de la constitución? ¿de qué manera este crecimiento afectó o fue afectado por la participación?

La Constitución del 2008 no hace referencia solo a la participación política sino también a la participación en los procesos económicos. En el caso ecuatoriano, puesto que todo el sistema económico en su conjunto es definido por la Constitución como de economía social y solidaria, ello implica que la participación en la producción debe llevarse a cabo no solo mediante las formas cooperativas de organización productiva, sino además desarrollando la participación de los trabajadores en los sectores estatal y privado de la economía (TRUJILLO; GRIJALVA, 2010).

En efecto, lo que el modelo constitucional en realidad prioriza, al menos formalmente, es la economía popular y solidaria $^{21}$, la cual agrupa a sectores cooperativistas, asociativos y comunitarios, se rige por su propia ley (Art. 284), sus productos tienen prioridad en las compras públicas, y en las políticas estatales tanto comerciales (Art 306) como financieras (Art 311). Se prioriza el desarrollo de la producción nacional (art 304, 319.2) y de los pequeños y medianos productores (art 306) mediante políticas de promoción a las exportaciones y desincentivos específicos a las importaciones, así como políticas de precios que protejan la competencia (art 335).

El artículo 283 de la Constitución presenta una suerte de síntesis de los principios básicos del modelo de economía social y solidaria que la Constitución establece: "El sistema económico es social y solidario; reconoce al ser humano como sujeto y fin; propende a una relación dinámica y equilibrada entre sociedad, Estado y mercado, en armonía con la naturaleza; y tiene por objetivo garantizar la producción y reproducción de las condiciones materiales e inmateriales que posibiliten el buen vivir" (ECUADOR, 2008).

Este artículo de la Constitución ecuatoriana vincula dos conceptos estructurales en una relación de medio y fin: economía social y solidaria, por un lado, y buen vivir, por el otro. El buen vivir o sumak kawsay es un concepto alternativo a la concepción occidental economicista de desarrollo; evidencia una dinámica intercultural en tanto la Constitución lo cataloga bajo la categoría de un conjunto de derechos, especialmente sociales, pero a su vez remite a valores y visiones de los pueblos andinos (SANTOS, 2010) que destacan la búsqueda de la armonía del ser humano consigo mismo, con los otros y con la naturaleza. Lo que queremos destacar aquí es que, pese a las múltiples visiones sobre el buen vivir (PONCE, 2016), todas coinciden en la importancia de la participación para su consecución, como de hecho lo establece la propia 
Constitución ecuatoriana en su artículo 278. Así mismo el Plan Nacional del Buen Vivir 2013 - 2017 incluyen a la participación, junto con la diversidad cultural y la sustentabilidad entre las dimensiones básicas para la planificación, seguimiento y evaluación del proceso encaminado al Buen Vivir, fin central de dicho plan (SENPLADES, 2013).

La economía social y solidaria, en particular, enfatiza la participación democrática de quienes aportan con su trabajo en la gestión de los procesos productivos y, al mismo tiempo, la distribución equitativa de sus frutos entre todos ellos; propugna la primacía del trabajo sobre el capital y la provisión de bienes y servicios de óptima calidad a las y los consumidores, mediante un intercambio según las reglas del precio justo y de respeto a la diversidad étnica y cultural.

En términos del artículo 320 de la Constitución Política "En las diversas formas de organización de los procesos de producción se estimulará una gestión participativa, transparente y eficiente" (ECUADOR, 2008). Por su parte el artículo 276 hace referencia entre los objetivos del régimen de desarrollo al fomento de la participación y el control social.

En definitiva, conforme a la Constitución del 2008 debía impulsarse no solo mayor participación política sino también una amplia participación en la economía, lo cual debía traducirse en un importante desarrollo de las cooperativas, las formas comunitarias de organización económica de los pueblos indígenas y el trabajo autónomo, la cogestión de los trabajadores en empresas públicas y privadas, y la planificación participativa.

Este horizonte para la organización económica tiene relativo sentido en un país como Ecuador en que más del $60 \%$ del empleo corresponde al sector cooperativo, y de pequeñas y medianas empresas, en que hay miles de pequeñas unidades productivas parte de las cuales cubren la mayor parte de la producción agrícola para consumo nacional, en que las comunidades indígenas mantienen fuertes lazos de solidaridad también en su organización productiva, y en que gran parte de los recursos financieros, especialmente el microcrédito (66\% frente al $34 \%$ de los bancos privados), están ubicados en este sector (RHON, 2016).

Pese a importantes esfuerzos institucionales y normativos relativos al sector de economía social y solidaria, esta no se convertido en eje de la política económica (BUENDIA, 2016). Luego de dictada la Constitución se han producido cambios como la creación de un Instituto de Economía Popular y Solidaria, la promulgación de una ley 
específica en el 2011 y su reglamento, la creación de la Superintendencia de Economía Social y Solidaria, y de la Corporación Nacional de Finanzas Populares y Solidarias en el 2012, legislación conexa de producción, finanzas y control monopólico, y ciertos programas de compras públicas a pequeños y medianos productores; sin embargo, no puede decirse que en los gobiernos de Correa este tipo de organización de la producción o las finanzas haya tenido máxima prioridad e impulso decisivo. Al menos, no ha constituido, como la Constitución dispone, el centro de la política económica del gobierno ${ }^{22}$.

En la práctica, en lugar de priorizar el desarrollo de las formas cooperativas de la economía lo que se ha observado en Ecuador durante el último decenio es un fuerte crecimiento del sector estatal de la economía en hidrocarburos, telecomunicaciones, hidroeléctricas, banca y medios de comunicación. Este crecimiento de la inversión pública ha sido durante los últimos años el motor de la economía ecuatoriana ${ }^{23}$, y fue financiado principalmente con rentas obtenidas por la exportación de petróleo, mientras los precios se mantuvieron altos, y de mejoras en la recaudación tributaria. Sin embargo, también las empresas públicas deberían, según la Constitución, ser espacios de participación en que los trabajadores ejerzan sus derechos. Paradójicamente, como veremos, se ha producido una restricción de la participación de los trabajadores en dichas empresas y en el servicio público.

Conforme al modelo constitucional de economía, los trabajadores debían aumentar su participación en empresas públicas y privadas. No obstante, luego de varios años de vigencia de la Constitución del 2008 lo que se observa es un debilitamiento notable del poder de los sindicatos, del derecho a la huelga y en general de su capacidad de negociación colectiva. Este debilitamiento, paradójicamente, se inició incluso durante la propia Constituyente del 2008, cuando ésta emitió varias decisiones denominadas mandatos constituyentes, alguno de ellos incluso contrarios al derecho de sindicalización reconocido por la normativa de la OIT suscrita por el Estado ecuatoriano ${ }^{24}$.

Posteriormente las políticas y normativas laborales de nivel administrativo han venido contrariando derechos laborales establecidos en el artículo 326 numerales 13 y 14 de la Constitución al establecer condiciones, plazos o efectos restrictivos de la sindicalización y la negociación colectiva, especialmente de empleados públicos. Pero la medida más radical en esta dirección fue la adoptada mediante enmienda constitucional en diciembre del 2015. Desde la entrada en vigor de esta reforma, las relaciones laborales de todos los trabajadores de las empresas públicas y del sector público en general pasaron 
de la regulación del Código del Trabajo a la de la Ley de Servicio Público. Este cambio implicó, en los hechos, restricciones a la sindicalización, prohibición de huelga en la prestación de servicios públicos y grave disminución o pérdida del poder de negociación colectiva de los trabajadores, justamente en un período de fuerte expansión del número de personas empleadas en el sector público.

Si bien es cierto que en Ecuador se produjeron abusos en cuanto a beneficios obtenidos por ciertos sindicatos públicos, ello no justifica violaciones a los derechos constitucionales e internacionales de sindicalización, huelga y negociación colectiva. En efecto, a la enmienda constitucional no siguió tampoco ninguna reforma en la Ley de Servicio Público o leyes conexas para asegurar, si bien en términos razonables, tales derechos de los servidores públicos, como establecen los Convenios pertinentes de la OIT $^{25}$, y han sugerido sus múltiples observaciones e informes al Estado ecuatoriano (GARBAY, 2014). De hecho, en las fechas de discusión de las enmiendas constitucionales la OIT mediante su Comisión de Aplicación de Normas realizó una serie de observaciones al Estado ecuatoriano a este respecto ${ }^{26}$. En definitiva, es paradójico que bajo una Constitución que destaca tanto la participación se hayan limitado estos derechos cruciales de los trabajadores.

\section{CONCLUSIONES}

Generalmente se identifica el extractivismo exclusivamente con un modelo o política económica, pero, como sugerimos a lo largo de este ensayo, su influencia puede gravitar más allá de los procesos económicos sobre ámbitos tan diversos como la participación, la educación, el trabajo o el sistema de justicia. En efecto, para poder concretar la explotación de recursos naturales las políticas extractivistas requieren un fuerte control social del Estado que convierte a la participación en fuente de legitimación, en lugar de que ésta sea un mecanismo de expansión de la democracia. Este control social exige una centralización del poder que por su naturaleza es contrario o al menos restrictivo de la participación democrática, la autonomía plurinacional, y con mucha frecuencia del ejercicio de otros derechos como los de asociación, expresión y opinión. En definitiva, el extractivismo como modelo económico requiere determinadas condiciones políticas.

En el caso ecuatoriano, aun reconociendo una importante modernización de infraestructura y redistribución socioeconómica, es innegable que luego de la R. Fac. Dir. UFG, v. 41, n.2, p.134-168, maio / ago. 2017 
Constitución del 2008 se mantiene la misma matriz productiva. La dinámica de la economía ecuatoriana sigue atada a las exportaciones de petróleo, y las expectativas del gobierno se centran ahora en la explotación minera. Entre otras variables, son las necesidades políticas del modelo extractivista las que han impulsado en Ecuador la centralización del poder en un régimen hiper-presidencialista. Claro ejemplo de ello son los bloqueos desde el ejecutivo a consultas como las antes analizadas a la Ley de Minería, y a la explotación del Yasuní; así como los recortes a la autonomía y participación de los pueblos indígenas en ámbitos como la educación intercultural y la justicia comunitaria, desde los cuales podrían surgir, y de hecho han surgido, formas directas o indirectas de resistencia a estas políticas ${ }^{27}$.

Los recursos obtenidos mediante el extractivismo, en el caso ecuatoriano las rentas del petróleo han financiado a su vez la actividad de una numerosa burocracia y de empresas públicas en sectores estratégicos de la economía, como energía, telecomunicaciones, recursos naturales no renovables, entre otros. Se busca de esta manera proveer especialmente de servicios públicos que contribuyan a cierta redistribución socioeconómica. Sin embargo, este proceso nuevamente se genera a partir de una centralización y ejercicio vertical del poder que ha implicado menor participación de los trabajadores mediante la restricción de los derechos constitucionales de sindicalización, huelga y negociación colectiva.

Por otra parte, y como es reconocido incluso por personeros oficialistas, en Ecuador las cooperativas, comunidades y otras formas de economía social y solidaria no se han desarrollado en la medida que lo plantea la Constitución. Puesto que estas formas de organización productiva conjugan capital y trabajo, ampliando la participación de los propios trabajadores, ésta falta de desarrollo implica también un débil crecimiento de la participación en los procesos productivos.

Que hemos aprendido:

La participación verdaderamente democrática debe ser inducida desde abajo, desde la sociedad, de forma autónoma, y el Estado debe responder a esta demanda. La participación vertical inducida desde el Estado es generalmente más una forma de legitimación y concentración que de redistribución del poder.

El hiperpresidencialismo no es solo una concentración del poder en el Ejecutivo o en el presidente en términos de la institucionalidad estatal, sino que esta centralización del poder político tiene consecuencias en la sociedad civil mediante la 
instrumentalización, reducción, regulación o incluso criminalización de la participación de las organizaciones sociales y de los individuos.

El hiperpresidencialismo es una forma política funcional al extractivismo, el cual requiere imponer de forma autoritaria la extracción de recursos naturales, en ese proceso los derechos son manipulados como retórica justificatoria de ese ejercicio del poder y dejan de ser límites o direccionamientos efectivos del mismo.

No es estratégico ni tiene proyecciones políticas caer simplemente en una “desilusión con el Estado". Estos años de experiencia del ciclo progresista deben llevar a una sería reflexión sobre las relaciones entre sociedad y Estado, entre movimientos sociales e instituciones, entre lucha social y constitución.

La independencia de los jueces y tribunales ordinarios, constitucionales y electorales es indispensable para que exista y se profundice la democracia. Estos jueces protegen derechos esenciales para la democracia como son las libertades de asociación, opinión, expresión, libertad de información y derechos electorales. Por el contrario, la dependencia política de estos jueces del ejecutivo puede ser usada para la criminalización de la protesta social y la limitación o violación de otros derechos consustanciales a una democracia más profunda.

La Constitución no es el final sino el comienzo de un proceso de cambio social. Debe ser vista como un programa político que debe defenderse en cada ley, cada reglamento, cada política pública, y en la integración y actuación de cada institución pública. De otra forma, los principios constitucionales pueden ser profundamente desvirtuados y vulnerados en la fase post-constituyente, dando lugar a una desconstitucionalización.

El cambio social no puede ser inducido desde un Estado que de medio pasa a convertirse en fin. El voluntarismo vertical y autoritario del Estado expresado en la expansión de burocracia, regulaciones, control e incluso recursos puede ser altamente ineficiente en términos de transformación estructural. Es la sociedad la que mediante una participación activa y autónoma debe permear al Estado, para que éste pueda desatar y acompañar procesos estructurales de cambio social y económico.

\section{REFERÊNCIAS}

AHUMADA, María de los Ángeles. "Neoconstitucionalismo y Constitucionalismo" en Paolo Comanducci, Maria de los Angeles Ahumada y Daniel González, Positivismo 
Jurídico y Neoconstitucionalismo. Madrid: Fundación Coloquio Jurídico Europeo, 2009.

ANDRADE, Pablo. El reino (de lo) imaginario: Los intelectuales políticos ecuatorianos en la construcción de la Constitución de 2008 (Tema Central). En Ecuador Debate. La cuestión de los intelectuales, Quito: CAAP, (no. 85, abril 2012): pp. 35-47.

BERNAL PULIDO, Carlos. El Derecho de los Derechos. Bogotá: Universidad Externado de Colombia, 2005.

BUENDÍA, Fernando. Leyes para el Buen Vivir en Materia Económica aprobadas por la Asamblea Nacional a partir del año 2008 al 2015 en Marco Navas y Pabel Muñoz (editores), Nueve Años de Desarrollo Constitucional. Quito: El Telégrafo, 2016.

BUSTOS, Andrea. EI Reconocimiento Constitucional del Derecho Colectivo a la Educación Intercultural de los Pueblos Indígenas en el Ecuador. Quito: Corporación de Estudios y Publicaciones, 2014.

CASTRO, José Luis. La Silla Vacía como Mecanismo de Participación Ciudadana. Tesis para la obtención del título de abogado - Pontificia Universidad Católica del Ecuador, 2014.

CÓRDOVA, Holguer. Derechos sin Poder Popular. Quito: Centro Andino de Estudios Estratégicos, 2013.

CORTE CONSTITUCIONAL DEL ECUADOR. Sentencia Nro. 113-14-SEP-CC

Caso Nro. 0731-10-EP (2014). Disponible en:

<https://www.corteconstitucional.gob.ec/sentencias/relatoria/relatoria/fichas/113-14-

SEP-CC.pdf > . Consultado en 29 de noviembre de 2017.

CUNILL, Nuria. Repensando lo Público a través de la Sociedad. Caracas: Editorial Nueva Sociedad, 1997.

ECUADOR. Constitución Política del Ecuador del 2008. Disponível em: <http://cancilleria.gob.ec/wp-content/uploads/2013/06/constitucion_2008.pdf>.

Consultado en 29 de noviembre de 2017.

FERRAJOLI, Luigi. Principia Iuris, Teoría del Derecho y de la Democracia. Madrid: Trotta, 2011.

FERRAJOLI, Luigi. Poderes Salvajes. La Crisis de la Democracia Constitucional. Madrid: Trotta, 2011.

FUNG, Archon; WRIGHT, Eric Olin. Democracia en Profundidad: nuevas formas institucionales de gobierno participativo con poder de decisión. Bogotá: Universidad Nacional de Colombia, 2003.

GARBAY, Ximena. Los Derechos de Sindicalización, Huegla y Negociación Colectiva: su posible aplicación en la Función Pública ecuatoriana. Quito: UASB, 2014. (Tesis de maestría en Derecho). 
GARGARElla, Roberto. La Sala de Máquinas de la Constitución. Buenos Aires: Katz Editores, 2014.

GRIJAlVA, Agustín. Courts and Political Parties - The Politics of Constitutional Review in Ecuador. Mauritius, 2010.

HELMKE, Gretchen. 2002. "The Logic of Strategic Defection: Court-Executive Relations in Argentina under Dictatorship and Democracy", en American Political Science Review, 96(2): 291-303.

LINARES, Sebastián. “La Independencia Judicial: Conceptualización y Medición” en Independencia Judicial en América Latina ¿de quién? ¿para qué? ¿cómo?, Edit. Germán Burgos. Bogotá: ILSA, 2003.

MALACATUS, Edwin. La revocatoria del mandato, como derecho establecido en la actual Constitución y legislación del Ecuador, respecto a sus alcances, requisitos y limitaciones. Quito, 2016, Tesis (Maestría en Derecho. Mención en Derecho Constitucional). Universidad Andina Simón Bolívar, Sede Ecuador.

NINO, Carlos Santiago. Fundamentos de Derecho Constitucional. Buenos Aires: Astrea, 2005.

NOGUERA, Albert; NAVAS, Marco. Los Nuevos Derechos de Participación ¿Derechos constituyentes o constitucionales? Valencia: Tirant lo Blanch, 2016.

ORRANTIA PARRA, Daniela. Análisis crítico de la planificación participativa en la elaboración del Plan Nacional del Buen Vivir 2013-2017. Quito, 2015, 84 p. Tesis (Maestría en Estudios Latinoamericanos. Mención en Política y Cultura). Universidad Andina Simón Bolívar, Sede Ecuador. Área de Estudios Sociales y Globales.

ORTÍZ, Richard. Reforma Electoral en Ecuador. Quito: Udla, 2017.

OSPINA, Pablo. "La Participación Ciudadana en Ecuador (2009-2012)" en Horizontes de los Derechos Humanos - Ecuador 2012. Quito, 2013.

PÁSARA, Luis. Independencia Judicial en la Reforma de la Justicia Ecuatoriana. Washington: DPLF, 2014.

PONCE, Fernando. Aportes del Buen Vivir a la Teorización sobre la Sociedad Justa, en Estado y Comunes. Quito: IAEN, (Nro.2 enero 2016).

RHON, Francisco (compilador), Economía Social y Solidaria - Historias y Prácticas de su Fortalecimiento. Quito: SEPS, 2016.

SANTOS, Boaventura de Sousa. Refundación del Estado en América Latina. Quito: Ediciones Abya Yala, 2010. 
SANTOS, Boaventura de Sousa; GRIJALVA, Agustín (editores). Justicia Indígena, Plurinacionalidad e Interculturalidad en Ecuador. Quito: Fundación Rosa Luxemburg, 2012.

SENPLADES, Plan Nacional del Buen Vivir 2013 - 2017, Quito, 2013.

TRUJILlO, Julio César; GRIJALVA, Agustín. El Fundamento Constitucional de la Nueva Economía en La Tendencia - Revista de Análisis Político, Quito (Nro. 10, Febrero - marzo 2010).

UPRIMNY, Rodrigo. Las transformaciones constitucionales recientes en América Latina: tendencias y desafíos. Garavito, César Rodríguez (org). El derecho en América Latina: un mapa para el pensamiento jurídico del siglo XXI. Buenos Aires: Siglo Veintiuno Editores, 2011: 109-137.

VARIOS. Independencia Judicial Insuficiente, prisión preventiva deformada, los casos de Argentina, Colombia, Ecuador y Perú. Washington: DPLF, 2013.

Artigo recebido 09 de outubro de 2017 e aceito em 30 de novembro de 2017

\footnotetext{
${ }^{1}$ En realidad, este es un término algo equívoco porque en tanto teoría hace referencia a asuntos y enfoques muy dispares y a veces hasta contradictorios. Puede ser mejor entendido como un conjunto de críticas y debates surgidos en la teoría del Derecho en relación al positivismo jurídico y el constitucionalismo clásicos.

${ }^{2}$ Para este análisis sobre Bolivia y Ecuador ver Boaventura de Sousa Santos, Refundación del Estado en América Latina, Quito, Editorial Abya Yala, 2010.

${ }^{3}$ En realidad, esta tensión entre un Ejecutivo fuerte, la participación y los derechos ha sido una constante en la historia constitucional latinoamericana, que antes se expresó en el conflicto entre constitucionalismo conservador, republicano y liberal. Ver Roberto Gargarella, op cit. Para una visión de esta tensión en la Constituyente ecuatoriana del 2008 ver Pablo Andrade, El reino (de lo) imaginario: los intelectuales políticos ecuatorianos en la construcción de la Constitución de 2008 (Tema Central). En Ecuador Debate. La Cuestión de los intelectuales, Quito: CAAP, (no. 85, abril 2012): pp. 35-47.
} 
${ }^{4}$ Nuria Cunill Grau, Repensando lo Público a través de la Sociedad, Caracas, Editorial Nueva Sociedad, 1997. Sobre las reformas constitucionales en los noventa en América Latina Cunill destaca que: "las reformas recurrentes se orientan a la introducción de las figuras de la iniciativa popular en la formación de las leyes y del referéndum en el nivel nacional, concebidos como derechos políticos de participación ciudadana. La Constitución de Argentina, reformada en agosto de 1994, incluye ambas figuras como derechos, y así también ocurre en las nuevas constituciones de Perú (septiembre de 1993), y de Colombia (octubre de 1991). Previamente habían sido incorporadas en la Constitución de Brasil, promulgada en octubre de 1988” (pág. 83)

${ }^{5}$ Es pública la multiplicación de la corrupción en el país. Así, por ejemplo, solo la empresa Oderbrecht, según el Departamento de Justicia de EEUU, pagó en Ecuador 33.5 millones de dólares en coimas para contratos públicos, aunque hay que precisar que a la presente fecha aún no se conocen los nombres de los respectivos funcionarios públicos.

${ }^{6}$ Para un muy buen panorama institucional y jurídico de estas instituciones ver Albert Noguera y Marco Navas, Los Nuevos Derechos de Participación ¿Derechos constituyentes o constitucionales?, Valencia, Tirant lo Blanch, 2016.

${ }^{7}$ Ver el Informe Criminalización de la Protesta Social Frente a Proyectos Extractivos en Ecuador, formulado por la Federación Internacional de Derechos Humanos (FIDH) en www.fidh.org

${ }^{8}$ Sobresalen varias protestas urbanas, marchas y protestas indígenas, como por ejemplo en el sur del país el caso de Saraguro en que se llegó a enjuiciar a varios manifestantes, así como conflictos en la Amazonía, en ocasiones con detenciones y enjuiciamientos penales a dirigentes sociales, debido al avance de los proyectos de minería impulsados por el gobierno y rechazados por estas organizaciones indígenas. También ha existido abuso de declaratoria del estado de excepción durante algunas de las mencionadas protestas.

${ }^{9}$ Es el caso de organizaciones ecológicas incluso de larga trayectoria como Pacha Mama y Acción Ecológica, o de carácter gremial como la Unión Nacional de Educadores (UNE). El decreto estableció un sistema de reinscripción y entrega de información de todas las ONGs del país, así como amplios criterios de creación y disolución jurídica de estas organizaciones que han dado lugar a una alta discrecionalidad del Estado.

${ }^{10}$ Muchos de los consejeros han estado vinculados al Ejecutivo anteriormente como altos funcionarios o asesores de ministros.

${ }^{11}$ Incluso los titulares en funciones se han vuelto a presentar a nuevos concursos para repetidos períodos, tal ha sido el caso del Fiscal General, El Contralor, El Defensor del Pueblo.

${ }^{12}$ Como indicamos esta Función fue creada en la Constitución del 2008, y está integrada por el Defensor del Pueblo, El Contralor General, un Consejo orientado a la participación ciudadana, entre otros. Sus principales competencias tienen que ver con rendición de cuentas, control de la corrupción e incentivo a la participación.

${ }^{13}$ Es también necesario señalar que las preguntas 1 y 2 de la Consulta planteada por el presidente Correa hacían en cambio referencia a restricciones al poder de los jueces para el otorgamiento de medidas cautelares, esto es medidas judiciales urgentes para la protección de derechos. Para este tipo de reformas, la Constitución en su Artículo 442 también limita la iniciativa del presidente, pues indica que no podrá plantear reformas constitucionales que restrinjan derechos o garantías constitucionales.

${ }^{14}$ Ver, por ejemplo, el informe del juez Baltazar Garzón y otros veedores internacionales sobre la justicia en en http://www.pensamientopenal.com.ar/system/files/2014/12/doctrina35446.pdf. También la obra R. Fac. Dir. UFG, v. 41, n.2, p.134-168, maio / ago. 2017

ISSN 0101-7187 
colectiva Independencia Judicial Insuficiente, prisión preventiva deformada, Washington, Due Process of Law Foundation, 2013. Para estudios de caso puede verse Luis Pásara, Independencia Judicial en la Reforma de la Justicia Ecuatoriana, DPLF, 2014.

15 En realidad, la reforma constitucional tuvo un carácter puramente orgánico, pero ilustra claramente como la organización del poder afecta de forma directa derechos y principios como el de debido proceso, independencia judicial, y por esta vía a todos los derechos justiciables.

${ }^{16}$ He analizado esta prohibición constitucional en Agustín Grijalva, Régimen Constitucional de Biodiversidad, Patrimonio Natural, Ecosistemas Frágiles, y Recursos Naturales Renovables, publicado en Grijalva A; Pérez E; y Oyarte R. Desafíos del Derecho Ambiental Ecuatoriano frente a la Constitución Vigente, Quito, CEDA, 2010.

17 También el gobierno, como parte de su respuesta, movilizó organizaciones afines y a 33 alcaldes amazónicos para recolectar firmas apoyando la explotación petrolera en el parque Yasuni.

${ }^{18}$ La autodefinición de los pueblos indígenas como nacionalidades se reconoció relativamente en la Constitución de 1998, cuyo artículo 83 hacía referencia a "los pueblos indígenas, que se autodefinen como nacionalidades de raíces ancestrales.

${ }^{19}$ En el 2012, tanto la Corte Interamericana en la sentencia del caso Sarayacu, como el Comité de Derechos Económicos, Sociales y Culturales de Naciones Unidas requirieron del Estado ecuatoriano implementar la consulta previa bajo condiciones de efectiva participación.

${ }^{20}$ Otro caso muy ilustrativo de esta tendencia es el caso Saraguro: el 17 de agosto del 2015 los indígenas Saraguros protestaron contra la minería y las enmiendas constitucionales cerrando la carretera que une a las ciudades de Cuenca y Loja; la Policía concurrió al sector y detuvo violentamente a unos 29 indígenas Saraguros, de los cuales fueron enjuiciados 22 y sentenciados 2 por paralización de servicios públicos. El proceso penal adoleció de graves violaciones al debido proceso y las sentencias (4 años de cárcel), según el propio Defensor Público, fueron desproporcionadas.

${ }^{21}$ Según el artículo 1 de la Ley ecuatoriana de Economía Social y Solidaria se entiende por economía popular y Solidaria a la forma de organización económica, donde sus integrantes, individual o colectivamente, organizan y desarrollan procesos de producción, intercambio, comercialización, financiamiento y consumo de bienes y servicios, para satisfacer necesidades y generar ingresos, basadas en relaciones de solidaridad, cooperación y reciprocidad, privilegiando al trabajo y al ser humano como sujeto y fin de su actividad, orientada al buen vivir, en armonía con la naturaleza, por sobre la apropiación, el lucro y la acumulación de capital.

${ }^{22}$ En efecto, hay un crecimiento de las unidades económicas del sector social y solidario, que pasaron de 6016 entre el 2012 y 2013 a 9139 en el 2016, un crecimiento del $52 \%$ que es reconocible pero no suficiente o proporcional luego de ocho años de vigencia de la Constitución. Ver el artículo de Hugo Jácome, Avances y Desafíos de la Economía Popular y Solidario en Ecuador, en Francisco Rhon, op cit.

${ }^{23}$ Esta situación comienza a cambiar desde el 2013 en que caen abruptamente los precios de hidrocarburos, bienes mineros y agrícolas. A raíz de esta crisis el gobierno de Correa ha iniciado la venta al sector privado de muchos de estos activos públicos.

${ }^{24}$ Son los mandatos 2, 4 y 8 que establecen límites a remuneraciones, indemnizaciones y revisión unilateral de cláusulas abusivas en el sector público. La Comisión de Expertos en Aplicación de Convenios y Recomendaciones de la OIT observó que tales disposiciones son contrarias al Derecho de Negociación Colectiva reconocida por Ecuador en el Convenio sobre Derecho de Sindicación y Negociación Colectiva. 
${ }^{25}$ Convenios $87,98,151$ y 154 de la OIT.

${ }^{26} \mathrm{Al}$ respecto el órgano de la OIT indica: "la Comisión constata con preocupación que la adopción de las enmiendas constitucionales supondría, en el estado actual de la legislación, una extensión del incumplimiento del artículo 4 del Convenio que reconoce el derecho de negociación colectiva de los trabajadores del sector público que no prestan sus servicios en la administración del Estado. En este sentido, la Comisión considera, al igual que el Comité de Libertad Sindical, que la discusión del proyecto de enmiendas constitucionales hace más urgente aún la necesidad de reformar la LOSEP y demás leyes administrativas de manera de ponerlas en conformidad con el Convenio." Observación del CEACR, adoptada en el 2015, 105 sesión de la OIT (Convenio 98).

${ }^{27}$ Por ejemplo, en el caso Saraguro, un tribunal indígena juzgó a los indígenas que desarrollaron protestas contra proyectos mineros en su sector. La justicia ordinaria desconoció la competencia de los jueces indígenas. Es claro también que la educación de las escuelas comunitarias indígenas está muy ligada a la valoración de la tierra y la naturaleza como fuente de vida no simplemente como recursos para explotación económica 